\title{
Numerical modeling of arsenic mobility during reductive iron-mineral transformations
}

$6 \quad{ }^{1}$ University of Western Australia, School of Earth and Environment, Western Australia

$7 \quad{ }^{2}$ National Centre for Groundwater Research and Training, Australia

$8 \quad{ }^{3}$ CSIRO Land and Water, Private Bag No. 5, Wembley, Western Australia, 6913

$9{ }^{4}$ Eawag, Swiss Federal Institute of Aquatic Science and Technology, Ueberlandstrasse 133, 8600 Dübendorf, 10 Switzerland

$11{ }^{5}$ Earth Sciences Division, Lawrence Berkeley National Laboratory, Berkeley, California

12 Earth System Science Department, Stanford University, Stanford, California 94305

13

14

15

16

17

18

19

Running Title: Arsenic mobilization during reductive dissolution of iron

This document is the Accepted Manuscript version of a Published Work that appeared in final form in Environmental Science and Technology, copyright (C) American Chemical Society after peer review and technical editing by the publisher. To access the final edited and published work see http://doi.org/10.1021/acs.est.5b05956 


\section{ABSTRACT}

22 Millions of individuals worldwide are chronically exposed to hazardous concentrations of arsenic from

23 contaminated drinking water. Despite massive efforts towards understanding the extent and underlying

24 geochemical processes of the problem, numerical modeling and reliable predictions of future arsenic

25 behaviour remain a significant challenge. One of the key knowledge gaps concerns a refined

26 understanding of the mechanisms that underlie arsenic mobilization, particularly under the onset of

27 anaerobic conditions, and the quantification of the factors that affect this process. In this study, we focus

28 on the development and testing of appropriate conceptual/numerical model approaches to represent and

29 quantify the reductive dissolution of iron oxides, the concomitant release of sorbed arsenic and the role

30 of iron mineral transformations. The initial model development in this study was guided by data and

31 hypothesized processes from a previously reported, ${ }^{1}$ well-controlled column experiment in which

32 arsenic desorption from ferrihydrite coated sands by variable loads of organic carbon was investigated.

33 Using the measured data as constraints, we provide a quantitative interpretation of the processes

34 controlling arsenic mobility during microbial reductive transformation of iron oxides. Our analysis

35 suggests that the observed arsenic behaviour is primarily controlled by a combination of reductive

36 dissolution of ferrihydrite, arsenic incorporation into or co-precipitation with freshly transformed iron

37 minerals and partial arsenic redox transformations.

38

39

40

41

42

43

Keywords: arsenic, reactive transport, iron mineral transformations, surface complexation 
44 Introduction

45 Millions of humans worldwide are exposed to the consumption of groundwater contaminated with

46 arsenic concentrations that exceed the World Health Organization's acceptable drinking water limit of

$47 \quad 10 \mu \mathrm{g} / 1 .{ }^{2}$ Chronic exposure of humans to high concentrations of arsenic in drinking water is associated

48 with skin lesions, peripheral vascular disease, hypertension, black foot disease and a high risk of 49 cancer. $^{3}$ Under oxidizing aquifer conditions, at circum-neutral $\mathrm{pH}$, arsenic generally does not pose a 50 significant threat to groundwater resources as it strongly sorbs onto iron oxide minerals such as

51 ferrihydrite. ${ }^{2}$ However, the intrusion of reactive organic carbon from sources such as carbon-rich 52 sediments, constructed ponds, recent degradation of plants, and wastewater ${ }^{2,4,5}$ has in the meantime been 53 identified as triggers for microbially mediated reductive dissolution of these iron phases, accompanied 54 by the release of ferrous iron and trace elements such as arsenic. The latter occurs on one hand, due to 55 the loss of the sorption capacity associated with the dissolution of the iron oxides, ${ }^{2,5-10}$ and additionally, 56 although to a lesser extent, due to competitive desorption by the bicarbonate generated during oxidation 57 of organic carbon. ${ }^{2,11-13}$ Among a range of conceptual models, arsenic release triggered by reductive 58 dissolution of iron oxides has evolved as the most widely accepted cause for the widespread presence of arsenic in S/SE Asia groundwater, even though locally other mechanisms may also be responsible.

60 Additionally, associated with the redox transformations induced by labile organic carbon, arsenate 61 transforms to arsenite, which has in many instances been reported to sorb less strongly to iron oxides 62 compared to arsenate ${ }^{2,5,14-16}$ and thus appears to explain the often observed increased arsenic mobility in 63 reducing environments. Contradicting this view, various batch studies showed that at neutral pHs, which 64 are typical of many natural environments, arsenite sorbed to a similar or greater extent than arsenate on 65 hydrous ferric oxide and goethite. ${ }^{17-19}$ However in these studies the sorbed arsenic concentrations were unrealistically high compared to natural environments and in one of the studies the lowest of three 67 sorbed arsenic concentrations showed the reverse with approximately $30 \%$ more arsenate sorbed than 68 arsenite at $\mathrm{pH} 7^{17}$, highlighting the possible variations in the observed behavior. 
70 Further complexities in terms of understanding arsenic mobility arise where elevated concentrations of

71 dissolved ferrous iron promote a range of important iron mineral transformations towards more reduced

72 and/or more stable iron phases. A number of recent studies ${ }^{1,20-22}$ suggest that understanding how newly

73 formed iron minerals provide new sorption sites, with varying sorption capacities, ${ }^{17}$ that facilitate the

74 attenuation of arsenic, is a key issue for understanding arsenic mobility. Furthermore, the possibility of

75 the transformation reaction to incorporate arsenic into the iron mineral structure may also contribute to

76 arsenic attenuation. ${ }^{23,24}$ Experiments concerning the dissimilatory iron reduction of the common iron

77 oxide, ferrihydrite, have shown transformations to goethite and lepidocrocite at low ferrous iron

78 concentrations, and also to magnetite, at high ferrous iron concentrations. ${ }^{21,25-27}$ A limited number of

79 studies have successfully quantified iron oxide transformations in numerical models. ${ }^{21,26,28}$ However, $^{28}$

80 despite the apparent significance of these processes for controlling concentrations and mass fluxes of

81 arsenic under both natural conditions and in environments requiring remediation, they have yet to be

82 considered in the development, testing and application of numerical modeling frameworks for such

83 systems.

Therefore, this study was aimed at developing and evaluating a range of numerical modeling approaches

that can suitably quantify the role of the key geochemical processes associated with a subset of iron

87 mineral transformations and their impact on arsenic mobility. Our initial model development was guided

88 by experimental data and hypothesized processes that were derived from well-controlled column studies

89 in which arsenic mobilization from ferrihydrite-coated sands, by variable loads of lactate, was studied. ${ }^{1}$

90 Subsequently, a series of alternative conceptual models were investigated. Those alternative models

91 explore the impact of arsenic incorporation with magnetite and the (partial) oxidation of arsenite. ${ }^{23,24}$

92 For each model variant, model parameters were estimated through a calibration procedure using Particle

93 Swarm Optimization (PSO). ${ }^{29-31}$ 


\section{Materials and Methods}

\section{Data Set Description}

97 The model development was guided by a comprehensive data set collected during the laboratory column 98 study of Tufano and Fendorf. ${ }^{1}$ In their study, arsenic mobilization was investigated under both abiotic 99 and microbially induced iron-reducing conditions. Four columns were packed with ferrihydrite coated 100 quartz sand (iron content $83 \mathrm{mmol} \mathrm{kg}^{-1}$ ) loaded with arsenite in an anaerobic chamber (initial loading

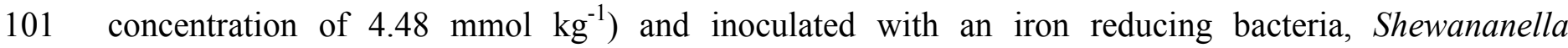
102 putrefacians strain $\mathrm{CN}-32$. The effective porosity of the column filled with ferrihydrite-coated sands 103 was determined to be 0.48 . An artificial groundwater solution was pumped from the bottom up through 104 each of the four columns at a rate of $6.8 \mu \mathrm{L} \mathrm{min}{ }^{-1}$, corresponding to $\sim 3$ pore volumes per day. Three of 105 the four column influent solutions contained lactate at concentrations of $7.7 \mathrm{mM}, 0.8 \mathrm{mM}$, and 0.08 $106 \mathrm{mM}$, respectively. A buffer (PIPES) was used to maintain a $\mathrm{pH}$ of 7.1. Water samples were analyzed 107 periodically over a 90 day period for effluent concentrations. In addition to the columns that were 108 analyzed for aqueous concentrations, triplicate columns were run simultaneously and sacrificed after 11, 10952 , and 90 days respectively to analyze the iron mineralogy. Following on from this earlier work the 110 present study focuses on the development of a suitable reactive transport modeling approach and its use 111 for an in-depth data interpretation.

\section{Modeling approach and tools}

114 In the first step, the geochemical model PHREEQC-2 ${ }^{32}$ was used to model and reconstruct the initial 115 water, sediment and surface concentrations that prevailed within the columns at the start of the column 116 experiments. In parallel, a simple 1D flow model representing the column setup was constructed with 117 the USGS model MODFLOW. ${ }^{33}$ The flow model and the simulated initial concentrations formed the 118 basis for the subsequent transport simulations with the reactive multi-component transport code 119 PHT3D, ${ }^{34}$ which couples the transport simulator MT3DMS, ${ }^{35}$ and PHREEQC-2. A PSO code was 
120 written within the PEST++ YAMR run manager ${ }^{36}$, and linked with PHT3D, in order to estimate

121 adjustable model parameters. The sum of squared residuals between measured and modeled

122 concentrations was minimized for each investigated model variant, subject to the constraint that model

123 parameters agree with their corresponding values published in the literature as closely as possible. The

124 PSO calibration procedure was also used to address posterior parameter uncertainty for the chosen

125 conceptual model (see Supporting Information).

Conceptual model of biogeochemical processes and reaction network implementation

128 The reactive processes within the columns leading to arsenic release/attenuation were developed with a

129 focus on five key processes (i) arsenic desorption by chemical disequilibrium during pore water 130 replacement, (ii) sorption of arsenic on (freshly) transformed iron phases, (iii) arsenic release during 131 reductive dissolution of iron (iv), partial oxidation of arsenite to arsenate, and, (v) arsenite incorporation 132 with magnetite.

134 Four main conceptual models $(S 1-S 4)$ were identified and further refined and investigated through 135 varying the contributions of specific processes. They were translated into numerical models by 136 formulating a mix of equilibrium and kinetically controlled reactions. These four main conceptual 137 models, reported variants and the corresponding numerical model implementations are listed in Table 1.

\section{Modeling of initial experimental conditions}

140 Using PHREEQC-2 in batch mode phosphate and arsenic were sequentially pre-sorbed onto the

141 ferrihydrite coated sand. Arsenite and arsenate were decoupled from the overall redox equilibrium and 142 redox transformations were assumed to be kinetically controlled (see also Wallis et al. ${ }^{37}$ ). To simulate 143 sorption to mineral surfaces an electric double layer surface complexation model in accordance with 144 Dzombak and Morel $^{38}$ was employed. However, whilst keeping the Dzombak and Morel ${ }^{38}$ database 145 unchanged, the surface site densities of ferrihydrite (weak and strong site) were iteratively adjusted to 
146 eventually attain the measured $0.84 \mu \mathrm{mol} \mathrm{kg}^{-1}$ and $4.48 \mathrm{mmol} \mathrm{kg}^{-1}$ of phosphate and arsenic surface

147 loadings, respectively, while the ratio between weak and strong sites was kept constant. Phosphate was 148 considered in the surface complexation simulations due to its known, strong affinity for sorption and the 149 potential for competition with both arsenite and arsenate. ${ }^{39,40}$ The modeled initial water chemistry that 150 was derived through this procedure was utilized to define the initial conditions (Table SI1) for the 151 reactive transport model simulations.

\section{Reductive dissolution of iron}

154 In all investigated numerical model variants, the key reaction in the biotic experimental columns was the oxidation of lactate (electron donor) coupled to the reduction of ferrihydrite (electron acceptor):

$$
\mathrm{C}_{3} \mathrm{H}_{5} \mathrm{O}_{3}^{-}+4 \mathrm{Fe}(\mathrm{OH})_{3}+7 \mathrm{H}^{+} \rightarrow \mathrm{C}_{2} \mathrm{H}_{3} \mathrm{O}_{2}^{-}+\mathrm{HCO}_{3}^{-}+4 \mathrm{Fe}^{2+}+10 \mathrm{H}_{2} \mathrm{O}
$$

Note, that ferrihydrite is here, both for simplicity and to represent natural variation, represented as $\mathrm{Fe}(\mathrm{OH})_{3}$, while recent work by Michel et al. ${ }^{41}$ suggests a stoichiometry $\mathrm{Fe}_{10} \mathrm{O}_{14}(\mathrm{OH})_{2}$ for ferrihydrite in

its pure form. To account for the kinetic control of the reaction the lactate degradation rate $R_{l a c}$ is described by a standard Monod-type rate expression:

$$
R_{l a c}=\alpha\left(\frac{\left[\mathrm{Fe}(\mathrm{OH})_{3}\right]}{k_{f e r r i}+\left[\mathrm{Fe}(\mathrm{OH})_{3}\right]}\right)\left(\frac{C_{l a c}}{k_{l a c}+C_{l a c}}\right)
$$

161 where $\alpha$ is a rate constant, $\left[\mathrm{Fe}(\mathrm{OH})_{3}\right]$ and $C_{\text {lac }}$ are the concentrations of ferrihydrite and lactate, and $\mathrm{k}_{\text {ferri }}$ and $\mathrm{k}_{\mathrm{lac}}$ are the half saturation constants for ferrihydrite and lactate, respectively.

\section{Iron mineral transformations}

165 Within the columns, EXAFS spectroscopy demonstrated that during the experiments a partial 166 transformation of ferrihydrite to magnetite occurred. This was attributed to the reductive dissolution of 167 ferrihydrite, which produces ferrous iron. Based on the findings of Hansel et al. ${ }^{21,42}$ and Tufano et al. ${ }^{26}$ it 168 was assumed that when dissolved ferrous iron occurs in excess of $2 \times 10^{-4} \mathrm{~mol} \mathrm{~L}^{-1}$ it starts to catalyze the 
170 originally proposed rate expression for magnetite precipitation of Tufano et al. ${ }^{26}$ was modified and a 171 term was added that allows for the limitation of available surface sites. ${ }^{43}$

$$
R_{\text {magn-ppt }}=-k_{\text {magn-pptn }} \max \left(0,\left[1-\frac{K_{\text {sp(magn })}}{I A P_{\text {magn }}}\right]\right)\left(\frac{\left[F e^{2+}\right]}{K_{\text {magn_pptn }}^{\text {thres }\left(F e^{2+}\right)}+\left[F e^{2+}\right]}\right)^{x}\left(0, \frac{\left.\left[F e(O H)_{3}\right]-C_{m}\right)}{\left[F e(O H)_{3}\right]}\right)
$$

172 where $k_{\text {magn-pptn }}$ is the effective rate coefficient, determined through model calibration, $I A P_{\text {magn }}$ is the 173 ion activity product of the aqueous solution, $K_{s p(m a g n)}$ is the solubility product for magnetite, $174 K_{\text {magn_pptn }}^{\text {thres }\left(F e^{2+}\right)}$ is a threshold term describing the aqueous concentration of $\left[F e^{2+}\right]$, which requires an 175 exponential term $(x)$ set at $3,\left[\mathrm{Fe}(\mathrm{OH})_{3}\right]$ is the concentration of ferrihydrite and $C_{m}$ is the ferrihydrite 176 concentration at which magnetite precipitation effectively stalls.

\section{Arsenite incorporation with magnetite}

179 The possibility of arsenite accumulation via precipitation was considered in model variants $S 2$ and $S 4$ 180 since a number of studies have observed decreasing aqueous arsenic concentrations while Fe mineral 181 transformations occurred. ${ }^{23,44}$ Furthermore, Wang et al. ${ }^{45}$ analyzed the interaction of As(III) with 182 magnetite during its precipitation at differing As/Fe ratios. They characterized the samples using 183 EXAFS spectroscopy to identify whether the uptake was via adsorption or precipitation; at lower ratios 184 the uptake of $\mathrm{As}(\mathrm{III})$ was predominately a result of sorption, while at higher ratios (As/Fe 0.333$)$ the 185 formation of a surface precipitate became increasingly dominant. The stoichiometry of the reaction was 186 assumed to be:

$$
\mathrm{Fe}^{2+}+2 \mathrm{Fe}^{3+}+2 \mathrm{H}_{3} \mathrm{AsO}_{3}+\mathrm{H}_{2} \mathrm{O} \rightarrow \mathrm{Fe}_{3} \mathrm{O}_{4} \mathrm{As}_{2} \mathrm{O}_{3}+8 \mathrm{H}^{+}
$$

The rate of the reaction was directly connected to the magnetite formation rate described by Eqn. (3), and an upper limit of 1:0.6, were tested and evaluated. 
193 Sorption of arsenic was assumed to occur in all model variants $(S 1-S 4)$ as (i) surface complexation 194 reactions with ferrihydrite and (ii) as surface complexation reactions with the newly formed magnetite. 195 An electrostatic double layer model based on Dzombak and Morel's ${ }^{38}$ surface complexation reactions 196 for arsenite, arsenate, and phosphate sorption onto ferrihydrite were used in the simulations. The model 197 was extended to utilize Dixit and Hering's ${ }^{17}$ arsenite sorption reactions onto magnetite and associated 198 surface site densities. Note, that while various sorption site densities of ferrihydrite and magnetite were 199 tested, the total number of sorption sites was stoichiometrically linked with the temporally varying 200 mineral concentrations. Other sorption reactions incorporated were ferrous iron, phosphate, ${ }^{46}$ and 201 bicarbonate, ${ }^{12}$ which introduced competitive sorption between arsenic and other ions for a finite number 202 of sorption sites. The stoichiometries of the considered surface complexation reactions are listed in 203 Table 2.

\section{Arsenite oxidation}

206 To investigate a range of different potential explanations for the observed As behaviour, a subset of the 207 simulations (S3 and $S 4$ ) incorporated the previously not considered possibility that some 208 arsenite/arsenate redox transformations have occurred. Initially, we tested the possibility that the 209 arsenite that was added during the preparation of the columns was oxidized to arsenate at varying 210 degrees shortly after sorbing on the ferrihydrite-coated sands. While the prerequisites for such an 211 oxidation to occur were considered to be reasonably unlikely, a partial, photo-induced ${ }^{47}$ oxidation or an 212 oxidation via intermediate Fe(III) phases was reported elsewhere ${ }^{48}$ for a Fe(III)-goethite system.

214 Arsenate reduction

215 While arsenite and arsenate were decoupled from the overall redox equilibrium, kinetically controlled 216 arsenate reduction to arsenite was still assumed to occur in the three lactate-amended columns, except 217 for model variants $S 1$ and $S 2$, which assumed that As persisted as arsenite throughout the entire 
218 experiment. The rate expression describing this reaction was dependent on both arsenate and lactate

219 concentrations using a standard Monod-type expression:

$$
R_{\text {As }(v) \text { red }}=\alpha\left(\frac{C_{a q u A s(v)}}{k_{a q u A s(v)}+C_{a q u A s(v)}}\right)\left(\frac{C_{l a c}}{k_{l a c}+C_{l a c}}\right)
$$

220 where $\alpha$ is a rate constant, $C_{a q u A s(v)}$ and $C_{\text {lac }}$ are the concentrations of arsenite and lactate, and

$221 k_{a q u A s(v)}$ and $\mathrm{k}_{\mathrm{lac}}$ are the half saturation constants for arsenite and lactate, respectively.

\section{Model development and calibration strategy}

224 The model development started with the numerical implementation of the initial conceptual 225 hydrochemical model of Tufano and Fendorf ${ }^{1}(S 1)$. A manual trial-and-error calibration procedure was 226 employed in order to provide a suitable set of initial parameter estimates for the subsequent automatic 227 calibration. This approach was repeated for the revised conceptual models in which initial arsenite 228 oxidation $(S 3, S 4)$ and arsenic incorporation with magnetite ( $S 2$ and $S 4)$ was considered. The model 229 parameters associated with each variant of the numerical implementation were then estimated by 230 minimizing the sum of squared residuals between model-simulated and experimentally measured 231 results. The Gauss-Levenberg-Marquardt method was initially attempted, to further refine the model 232 parameters. $^{49-51}$ However, due to the severe nonlinearity of the inverse problem in this study, 233 convergence was difficult to achieve with this algorithm. Therefore, the heuristic PSO method was 234 implemented, which is known for its relatively high convergence rates (especially for Pareto analyses), 235 and its effectiveness at avoiding local minima, ${ }^{29}$ which is a significant issue for severely nonlinear 236 optimization problems. The parameters to be estimated included a number of kinetic reaction rate 237 constants, arsenic surface complexation constants, and surface site densities associated with specific 238 iron minerals (Table 2). These parameters were largely interdependent of each other. Furthermore, 239 calibration was constrained to produce an arsenic surface loading of $4.25 \times 10^{-5} \mathrm{M}$, corresponding to the 240 value measured by Tufano and Fendorf ${ }^{1}$ as well as by pre-defined degrees of initial arsenite oxidation

241 (model variants $S 4 a$ and $S 4 b$ ). Prior information, obtained from literature ${ }^{17,38,52}$ and expert knowledge, 
242 was used to define the upper and lower bounds of each parameter, and subsequently to obtain an 243 approximately Bayesian estimate of the parameters.

\section{Results and Discussion}

\section{Reductive dissolution of ferrihydrite and fate of ferrous iron under varying lactate loads}

For all investigated conceptual models, simulations reproduced the temporal concentration changes of iron that were induced by the amendment and transformation of varying lactate concentrations in conjunction with the reductive dissolution of ferrihydrite. Figure 1 shows selected, representative results 250 for variant $S 4 b$. Similar results were, however, obtained for all other discussed model variants. In the 251 three columns in which lactate was added, dissolved ferrous iron concentrations increased significantly until day 20 of the column operation. Larger and faster increases were associated with the addition of

$7.7 \mathrm{mM}$ and $0.8 \mathrm{mM}$ compared to the addition of $0.08 \mathrm{mM}$, while virtually no difference was found between the addition of $7.7 \mathrm{mM}$ and $0.8 \mathrm{mM}$ lactate. The model replicated these observations closely once a suitable value for the half-saturation constant in the Monod term for lactate (Eqn. 2) was selected.

The results for all model variants are also consistent with the interpretation that the time lag in the breakthrough of ferrous iron at the column effluent is due to the retarded transport of ferrous iron that is freshly released during ferrihydrite dissolution. Breakthrough of the ferrous iron in the column effluent attained throughout the column, i.e., newly released ferrous iron was no longer sorbed, a substantially higher breakthrough concentration was observed. This is illustrated in Figure 2, which shows simulated concentration profiles for model variant $S 4 b$ for the $7.7 \mathrm{mM}$ lactate amendment cases at various times 
268 Following the initial breakthrough of dissolved ferrous iron in the column effluent, the concentrations

269 peaked quickly before decreasing successively (Figure 1). The decrease was more pronounced in the 270 case of $7.7 \mathrm{mM}$ and $0.8 \mathrm{mM}$ than the $0.08 \mathrm{mM}$ lactate amendment. The observed decreases can be 271 replicated by the numerical model as a result of the successively lower rate of ferrihydrite dissolution 272 within the column, which causes a slowing release of ferrous iron. This decrease is not outweighed by 273 the simultaneous decrease in available sorption sites, which induces the release of ferrous iron.

\section{Iron mineral transformations}

276 The Fe-EXAFS results for the three lactate amended columns, as discussed in ${ }^{1}$ showed that specifically 277 in the early phase of the experiment (before day 11) ferrihydrite was partially transformed to magnetite 278 (Figure 3) while, on the other hand, no magnetite was found in the abiotic column. No other iron minerals were identified by EXAFS spectroscopy, i.e., no goethite or lepidocrocite formed prior to 280 magnetite. This may be due to the oxyanions (arsenite and phosphate) poisoning the transformation. ${ }^{53,54}$ 281 The observations are in line with previous studies ${ }^{27,42}$ which have shown that in chloride-dominated 282 systems, at neutral $\mathrm{pH}$, with high ferrous iron concentrations magnetite is the primary transformation 283 product of ferrihydrite. As shown in Figure 3, our calibrated model was able to closely replicate those 284 observations. In the lactate amended columns the highest iron transformation rates occurred in the early 285 phase of the experiments once the ferrous iron that was produced during reductive dissolution of 286 ferrihydrite started to successively increase and exceed the set threshold concentration of $2 \times 10^{-4} \mathrm{~mol} \mathrm{~L}^{-1}$ 287 of $\mathrm{Fe}^{2+}$. After an initial rapid increase of the magnetite formation rate, peaking after 5-6 days in the $2887.7 \mathrm{mM} / 0.8 \mathrm{mM}$ lactate columns, to $7-8$ days in the $0.08 \mathrm{mM}$ lactate column, the iron transformation 289 rates decrease quickly, before stalling 7 to 12 days after the start of the experiments (see Figure 3). In 290 the model, which closely replicated the fractions measured by Tufano and Fendorf, ${ }^{1}$ this occurred when 291 about $10 \%$ of the originally present ferrihydrite was consumed or transformed and the available sorption 292 sites for magnetite formation had decreased accordingly. As magnetite consists of Fe(II) in octahedral 293 sites and $\mathrm{Fe}(\mathrm{III})$ in both tetrahedral and octahedral coordination, the presence of tetrahedral $\mathrm{Fe}(\mathrm{III})$ at the 
294 ferrihydrite surface controls the formation of magnetite. ${ }^{43}$ Thus surface passivation may limit magnetite 295 formation once tetrahedral Fe(III) surface sites have been exhausted. ${ }^{27}$ Zachara et al. $^{55}$ also discussed 296 that high bicarbonate concentrations may impede conversion of ferrihydrite to magnetite by minimizing 297 site accessibility through bicarbonate sorption. In the column study, bicarbonate concentrations were not 298 particularly high. However, the elevated concentrations of sorbed arsenic on the sites provided by 299 ferrihydrite may have a similar effect on minimizing site accessibility and thus play a role on limiting 300 the formation of magnetite. ${ }^{56}$

302 Compared to the rate expression proposed by Tufano et al., ${ }^{26}$ a more process-based formulation for 303 magnetite formation (Eqn 3) could potentially employ a rate-dependence on sorbed ferrous iron 304 concentrations $^{55,57}$ rather than the aqueous ferrous iron concentration. The impact of changing the rate 305 expression was evaluated for the model of the $7.7 \mathrm{mM}$ lactate amended column. The results show that 306 for a sorbed ferrous iron threshold concentration of $3.5 \times 10^{-3} \mathrm{~mol} \mathrm{~L}^{-1}$, simulated aqueous and mineral 307 concentrations remain similar to the results obtained when employing Eqn 3.

\section{Arsenic mobilization and attenuation}

\section{Original conceptual model after Tufano and Fendorf (S1)}

312 proposed by Tufano and Fendorf $^{1}(S 1)$, which assumed that all arsenic persisted as arsenite, allowed to 313 mostly replicate the observed data of the abiotic (no lactate amendment) experiment after day 10 (Figure 314 4). Nevertheless, a deviation between the model and the observations persisted in that the simulations 315 did not capture the initial effluent arsenite concentration drop that occurred prior to day 10 . This 316 discrepancy may be attributed to weaker outer-sphere arsenic complexes undergoing rapid desorption, a 317 process that was not captured by our surface complexation model implementation. 
319 For this model variant (S1), however, in the simulations of the lactate-amended columns, the 320 experimentally observed arsenite breakthrough concentrations could not be reproduced. For example, in 321 the column in which $7.7 \mathrm{mM}$ lactate was amended, observed arsenic concentrations decreased 322 dramatically during the first 12 days (Figure 4). In contrast to those observations, dissolved arsenite 323 breakthrough concentrations increased significantly in all preliminary model simulations as a result of 324 the lactate-induced reductive dissolution of ferrihydrite and the associated loss of sorption sites (Figure 325 4). Tufano and Fendorf ${ }^{1}$ suggested that the observed sharp initial decrease in arsenic concentrations may 326 be due to the newly generated sorption capacity of the freshly formed magnetite. This hypothesis was 327 evaluated by successively increasing the sorption site density of the freshly precipitated magnetite. The 328 simulations showed that a sorption site density of $3 \mathrm{~mol}$ per mol of magnetite would be required to 329 replicate the observed concentration decrease. This is implausible as magnetite was previously 330 estimated to have a 6 times lower specific surface area than ferrihydrite, ${ }^{17}$ which in the present study 331 would correspond to approximately $0.02 \mathrm{~mol}$ per mol of magnetite, i.e., $>120$ times less than our model332 estimated value. Furthermore sorption strengths of magnetite, as estimated by Dixit and Hering ${ }^{17}$ 333 through a batch/modeling study, showed similar strengths (surface complexation constants) for both 334 iron oxides and magnetite. Based on these modeling results it was concluded that it was unlikely that 335 'classic' equilibrium-type surface complexation reactions with magnetite could have been responsible 336 for the observed decline in dissolved arsenic concentrations.

\section{Revised conceptual models}

340 A key assumption of all initially investigated model variants was that arsenite was not allowed to be 341 incorporated into the structure of magnetite during transformation. This was based on the findings of 342 Coker et al., ${ }^{58}$ who concluded that arsenite could only exist as a surface complex. However a number of 343 other column studies ${ }^{15,23,44}$ have observed enhanced arsenite retention in conjunction with iron 344 transformations from ferrihydrite to magnetite. This suggests that the sink for arsenite may be 
345 precipitation during ferrihydrite transformation to magnetite. Therefore model variants that allowed

346 arsenite to be captured into the transforming magnetite were tested and evaluated for a range of different 347 As:Fe molar ratios. This additional process was appended to the original model, and the calibration 348 process was repeated with this model variant $(S 2)$. A relatively good representation of the observed 349 arsenic and iron concentrations was achieved (Fig SI2). However to attain this, the molar ratio of As:Fe 350 was 1:1.7. Furthermore, to achieve a satisfactory simulation of the observed arsenic breakthrough 351 behaviour, the initial arsenic surface loading in the column had to be increased to $7.6 \times 10^{-5} \mathrm{M}$ compared 352 to the $4.25 \times 10^{-5} \mathrm{M}$ reported by Tufano and Fendorf, ${ }^{1}$ which further reduces the plausibility of this 353 model variant.

\section{Redox transformations of arsenite (S3)}

356 Following from some initial test simulations of this conceptual model (see Supporting Information) this 357 variant was formally calibrated $(S 3)$. The calibration procedure resulted in estimates of the (i) initial 358 distribution of arsenite and arsenate (i.e., \% of oxidation prior to start of the experiments), (ii) arsenic 359 surface complexation reaction constants, (iii) surface site densities, (iv) kinetic reaction rate constants 360 for ferrihydrite dissolution/magnetite precipitation and As(V) transformation to As(III) (Table 2). With 361 the calibrated model it was possible to replicate all observed iron and arsenic concentrations from all 362 four column experiments with a single, consistent model. This is illustrated in Figure SI3, which shows 363 the comparison between the simulated and observed arsenic and ferrous iron breakthrough curves.

365 In the simulation of the abiotic column that shows a good agreement with the data, arsenic leaching 366 from the column occurs in the majority as arsenate. However, in the simulations of the lactate amended 367 model, the arsenate that was assumed to have formed during the experimental preparation was rapidly 368 reduced to arsenite once the lactate reduction caused a shift to reducing conditions. The rapid 369 transformation to arsenite in combination with the selected surface complexation constants that cause 370 arsenite to sorb more strongly, causes the modeled effluent arsenic concentrations to successively 
371 decrease within the first 20 days of the experiment (Figure 1). With reductive dissolution of iron

372 progressing in the lactate-amended columns, the continuous loss of ferrihydrite-associated sorption sites

373 causes arsenite to be released to the aqueous phase and effluent concentrations to steadily increase after 374 day 20.

376 The key for this variant to match the experimental data is a parameterization of the surface 377 complexation model that allows arsenite to sorb more strongly than arsenate. This agrees with the 378 results of Dixit and Hering's ${ }^{17}$ batch experiments at circum-neutral $\mathrm{pH}$. However, contradicting their 379 observations, several column studies ${ }^{15,23,24}$ have demonstrated arsenite to desorb more extensively than 380 arsenate.

\section{Model including arsenic incorporation with magnetite and arsenite oxidation (S4)}

383 In the final conceptual model variant, a combination of the previously discussed processes was 384 implemented into the model. Two slightly differing variants $(S 4 a, S 4 b)$ were considered, which 385 depended on the degree of arsenite oxidation that was occurring and therefore defining the initial 386 conditions. The first variant $(S 4 a)$ assumed a partial arsenite oxidation of $25 \%$ (during the experimental 387 setup) and the second variant $(S 4 b)$ assumed it to be $10 \%$. In each case, a good model fit was achieved, 388 primarily by allowing variations in the ratio of arsenic incorporation with magnetite (relative to 389 precipitating $\mathrm{Fe})$. Assuming $25 \%$ and $10 \%$ arsenite oxidation $(S 4 a, b)$, the simulated As:Fe molar ratio 390 was 1:4.5 and 1:3.1, respectively, highlighting that a decrease in the assumed arsenite oxidation requires 391 magnetite to more efficiently capture arsenite during the mineral transformation phase. However, with 392 the increased As:Fe ratio the initial arsenic surface loading had to be increased slightly to $4.9 \times 10^{-5} \mathrm{M}$ $393(S 4 a)$ and even more to $6.2 \times 10^{-5} \mathrm{M}$ in $S 4 b$. Simulation results for $S 4 b$ are displayed in Figure 1. 
396 Our modeling framework that was developed in this study provides a process-based description of the 397 complex interactions that evolve during the reductive dissolution of ferrihydrite and its partial 398 transformation to magnetite. The model investigations provided the basis for the re-interpretation of 399 some well-controlled, previously reported experiments that attributed significant arsenic attenuation to 400 the adsorption on neo-formed magnetite. Among the original and revised conceptual/numerical models 401 the variant $S 4$ appears to be the most plausible variant. These variants capture the observed arsenic and 402 iron breakthrough dynamics for variable loads of lactate amendment best, suggesting that arsenic 403 incorporation with magnetite in addition to sorption on mineral surfaces must also have occurred and 404 contributed substantially to the attenuation of aqueous arsenic concentrations. Furthermore, based on the 405 model results, we speculate that a small fraction of the arsenite may have been oxidized prior or around 406 the start of the column operations. In the unlikely case that arsenite oxidation had occurred to a 407 significantly larger extent, it could still only explain the observed arsenic breakthrough curves if 408 arsenate sorption to ferrihydrite under the experimental conditions was weaker than arsenite sorption, 409 which contradicts several column experiments that suggested that arsenite had a higher mobility ${ }^{15,23,24}$ 410 compared to arsenate.

412 Eventually this implies that in the short term the intrusion and degradation of organic carbon and the 413 coupled reductive dissolution of ferrihydrite is not enhancing arsenic release until ferrihydrite and the 414 associated sorption capacity are nearing depletion. If indeed arsenic precipitation during magnetite 415 formation was the dominant process for attenuating arsenic concentrations, then iron oxide 416 transformations may limit or delay arsenic release into the groundwater. However, where reducing 417 conditions already prevail, iron transformations (for example to goethite) may have been completed and 418 thus no additional attenuation of arsenic occurs. Our results call for additional experiments that further 419 investigate whether arsenite was incorporated in the structure of the transforming magnetite or rather 420 accumulated as an amorphous $\mathrm{As}(\mathrm{III}) / \mathrm{Fe}(\mathrm{III})$ precipitate on the magnetite surface. Such experiments 421 could also further clarify whether the model-derived As:Fe molar ratios are plausible. In addition the 
model framework should now be tested and extended for a variety of idealized laboratory conditions

423 and for data sets from controlled and well-characterized field experiments such as reported by Neidhardt 424 et al., ${ }^{20}$ and Harvey et al. ${ }^{59}$

425

426 Associated content

427

428

Supporting Information

429 Additional material includes additional descriptions, Tables and Figures related to various permutations 430 of the main 4 model variants. The Supporting Information is available free of charge on the ACS 431 Publications website at DOI: 10.1021/esxxxxx. Financial support was provided by an Australian 432 Postgraduate Award, the National Centre for Groundwater Research and Training (NCGRT) and 433 CSIRO Land and Water.

435 Author information

436 Corresponding Author*

437 Phone: +61 8 93336272; e-mail: Henning.Prommer@csiro.au

\section{Author Contributions}

440 J.R. developed and calibrated the model variants under the supervision of H.P., J.A.D. and A.S.

441 J.C., M.B. and S.F. provided input on various aspects of the conceptual models. All authors contributed 442 to the writing of the paper.

444 Notes: The authors declare no competing financial interest.

446 Acknowledgments 
447 This contribution received valuable input from Jungho Park, Ming Wu, Ilka Wallis, Katherine Tufano, 448 Ben Bostick, Jing Sun and 5 anonymous reviewers. Support for SF was provided partially by the U.S. 449 National Science Foundation (grant number EAR-0952019). Additionally, Dave Welter was extremely 450 helpful in implementing the PEST++ YAMR run manager for this study.

\section{Literature Cited}

(1) Tufano, K. J.; Fendorf, S. Confounding impacts of iron reduction on arsenic retention. Environ. Sci. Technol. 2008, 42, 4777-4783.

(2) Smedley, P. L.; Kinniburgh, D. G. A review of the source, behaviour and distribution of arsenic in natural waters. Applied Geochemistry 2002, 17, 517-568.

(3) Mukherjee, S.; Roy, M.; Dey, S.; Bhattacharya, R. K. A mechanistic approach for modulation of arsenic toxicity in human lymphocytes by curcumin, an active constituent of medicinal herb Curcuma longa Linn. J Clin Biochem Nutr 2007, 41, 32-42.

(4) McArthur, J. M.; Banerjee, D. M.; Hudson-Edwards, K. A.; Mishra, R.; Purohit, R.; Ravenscroft, P.; Cronin, A.; Howarth, R. J.; Chatterjee, A.; Talukder, T.; Lowry, D.; Houghton, S.; Chadha, D. K. Natural organic matter in sedimentary basins and its relation to arsenic in anoxic ground water: the example of West Bengal and its worldwide implications. Applied Geochemistry 2004, 19, 1255-1293.

(5) Fendorf, S.; Michael, H. A.; van Geen, A. Spatial and temporal variations of groundwater arsenic in South and Southeast Asia. Science 2010, 328, 1123-1127.

(6) Postma, D.; Larsen, F.; Minh Hue, N. T.; Duc, M. T.; Viet, P. H.; Nhan, P. Q.; Jessen, S. Arsenic in groundwater of the Red River floodplain, Vietnam: Controlling geochemical processes and reactive transport modeling. Geochimica et Cosmochimica Acta 2007, 71, 5054-5071.

(7) Berg, M.; Trang, P. T. K.; Stengel, C.; Buschmann, J.; Viet, P. H.; Van Dan, N.; Giger, W.; Stuben, D. Hydrological and sedimentary controls leading to arsenic contamination of groundwater in the Hanoi area, Vietnam: The impact of iron-arsenic ratios, peat, river bank deposits, and excessive groundwater abstraction. Chemical Geology 2008, 249, 91-112.

(8) Biswas, A.; Nath, B.; Bhattacharya, P.; Halder, D.; Kundu, A. K.; Mandal, U.; Mukherjee, A.; Chatterjee, D.; Morth, C. M.; Jacks, G. Hydrogeochemical contrast between brown and 
grey sand aquifers in shallow depth of Bengal Basin: consequences for sustainable drinking water supply. The Science of the total environment 2012, 431, 402-412.

(9) Nickson, R. T.; McArthur, J. M.; Ravenscroft, P.; Burgess, W. G.; Ahmed, K. M. Mechanism of arsenic release to groundwater, Bangladesh and West Bengal. Applied Geochemistry 2000, 15, 403-413.

(10) Polizzotto, M. L.; Kocar, B. D.; Benner, S. G.; Sampson, M.; Fendorf, S. Near-surface wetland sediments as a source of arsenic release to ground water in Asia. Nature 2008, 454, 505NIL_505.

(11) Anawar, H. M.; Akai, J.; Sakugawa, H. Mobilization of arsenic from subsurface sediments by effect of bicarbonate ions in groundwater. Chemosphere 2004, 54, 753-762.

(12) Appelo, C. A. J.; Van der Weiden, M. J. J.; Tournassat, C.; Charlet, L. Surface complexation of ferrous iron and carbonate on ferrihydrite and the mobilization of arsenic. Environ. Sci. Technol. 2002, 36, 3096-3103.

(13) Gao, X. B.; Wang, Y. X.; Hu, Q. H.; Su, C. L. Effects of anion competitive adsorption on arsenic enrichment in groundwater. J Environ Sci Heal A 2011, 46, 471-479.

(14) Stollenwerk, K. G.; Breit, G. N.; Welch, A. H.; Yount, J. C.; Whitney, J. W.; Foster, A. L.; Uddin, M. N.; Majumder, R. K.; Ahmed, N. Arsenic attenuation by oxidized aquifer sediments in Bangladesh. Science of the Total Environment 2007, 379, 133-150.

(15) Tufano, K. J.; Reyes, C.; Saltikov, C. W.; Fendorf, S. Reductive Processes Controlling Arsenic Retention: Revealing the Relative Importance of Iron and Arsenic Reduction. Environ. Sci. Technol. 2008, 42, 8283-8289.

(16) Nguyen Thi Hoa Mai, D. P., Pham Thi Kim Trang, Søren Jessen, Pham Hung Viet, Flemming Larsen. Adsorption and desorption of arsenic to aquifer sediment on the Red-River floodplain at Nam Du Vietnam. Geochimica et Cosmochimica Acta 2014, 142, 587-600.

(17) Dixit, S.; Hering, J. G. Comparison of arsenic(V) and arsenic(III) sorption onto iron oxide minerals: Implications for arsenic mobility. Environ. Sci. Technol. 2003, 37, 4182-4189.

(18) Manning, B. A.; Fendorf, S. E.; Goldberg, S. Surface structures and stability of arsenic(III) on goethite: Spectroscopic evidence for inner-sphere complexes. Environ. Sci. Technol. 1998, 32, 2383-2388.

(19) Raven, K. P.; Jain, A.; Loeppert, R. H. Arsenite and arsenate adsorption on ferrihydrite: Kinetics, equilibrium, and adsorption envelopes. Environmental science \& technology 1998, 32, 344349.

(20) Neidhardt, H.; Berner, Z. A.; Freikowski, D.; Biswas, A.; Majumder, S.; Winter, J.; Gallert, C.; Chatterjee, D.; Norra, S. Organic carbon induced mobilization of iron and manganese in a West Bengal aquifer and the muted response of groundwater arsenic concentrations. Chemical Geology 2014, 367, 51-62.

(21) Hansel, C. M.; Benner, S. G.; Neiss, J.; Dohnalkova, A.; Kukkadapu, R. K.; Fendorf, S. Secondary mineralization pathways induced by dissimilatory iron reduction of ferrihydrite under advective flow. Geochimica Et Cosmochimica Acta 2003, 67, 2977-2992.

(22) Jonsson, J.; Sherman, D. M. Sorption of As(III) and As(V) to siderite, green rust (fougerite) and magnetite: Implications for arsenic release in anoxic groundwaters. Chemical Geology 2008, 255, 173-181.

(23) Herbel, M.; Fendorf, S. Biogeochemical processes controlling the speciation and transport of arsenic within iron coated sands. Chemical Geology 2006, 228, 16-32.

(24) Kocar, B. D.; Herbel, M. J.; Tufano, K. J.; Fendorf, S. Contrasting effects of dissimilatory iron(III) and arsenic(V) reduction on arsenic retention and transport. Environmental science \& technology 2006, 40, 6715-6721.

(25) Yang, L.; Steefel, C. I.; Marcus, M. A.; Bargar, J. R. Kinetics of Fe(II)-Catalyzed Transformation of 6-line Ferrihydrite under Anaerobic Flow Conditions. Environ. Sci. Technol. 2010, $44,5469-5475$. 
(26) Tufano, K. J.; Benner, S. G.; Mayer, K. U.; Marcus, M. A.; Nico, P. S.; Fendorf, S. Aggregate-Scale Heterogeneity in Iron (Hydr)oxide Reductive Transformations. Vadose Zone J 2009, 8, 1004-1012.

(27) Benner, S. G.; Hansel, C. M.; Wielinga, B. W.; Barber, T. M.; Fendorf, S. Reductive dissolution and biomineralization of iron hydroxide under dynamic flow conditions. Environ. Sci. Technol. 2002, 36, 1705-1711.

(28) Prommer, H.; Davis, G. B.; Barry, D. A. Geochemical changes during biodegradation of petroleum hydrocarbons: field investigations and biogeochemical modelling. Org Geochem 1999, 30, 423-435.

(29) Coello, C. A. C.; Pulido, G. T.; Lechuga, M. S. Handling multiple objectives with particle swarm optimization. Ieee T Evolut Comput 2004, 8, 256-279.

(30) Eberhart, R., and J. Kennedy A new optimizer using particle swarm theory. Micro Machine and Human Science, Sixth International Symposium on 1995, 39-43.

(31) Kennedy, J. R., R. Eberhart, and Y. Shi. Swarm Intelligence. Morgan Kaufman Publishers Inc., San Francisco, CA. 2001.

(32) Parkhurst, D. L.; Appelo, C. A. J.; Geological Survey (U.S.): User's guide to PHREEQC (version 2) a computer program for speciation, batch-reaction, one-dimensional transport, and inverse geochemical calculations; U.S. Geological Survey : Earth Science Information Center, Open-File Reports Section distributor, 1999.

(33) Harbaugh, A. W.; Geological Survey (U.S.): MODFLOW-2000, the U.S. Geological Survey modular ground-water model user guide to modularization concepts and the ground-water flow process; U.S. Geological Survey ; Branch of Information Services distributor: Reston, VA, Denver, CO, 2000.

(34) Prommer, H.; Barry, D. A.; Zheng, C. MODFLOW/MT3DMS-based reactive multicomponent transport modeling. Ground Water 2003, 41, 247-257.

(35) Zheng, C. W., P.P. MT3DMS: A Modular Three-Dimensional Multispecies Transport Model for Simulation of Advection, Dispersion, and Chemical Reactions of Contaminants in Groundwater Systems; Documentation and User's Guide. 1999.

(36) Welter, D. E., White, J.T., Hunt, R.J., and Doherty, J.E.: Approaches in highly parameterized inversion-PEST++ Version 3, a Parameter ESTimation and uncertainty analysis software suite optimized for large environmental models; U.S. Geological Survey Techniques and Methods, book 7, 2015.

(37) Wallis, I.; Prommer, H.; Simmons, C. T.; Post, V.; Stuyfzand, P. J. Evaluation of Conceptual and Numerical Models for Arsenic Mobilization and Attenuation during Managed Aquifer Recharge. Environmental science \& technology 2010, 44, 5035-5041.

(38) Dzombak, D. A. M., Francois M.M.: Surface Complexation Modelling; Wiley: United States of America, 1990.

(39) Liu, F.; De Cristofaro, A.; Violante, A. Effect of $\mathrm{pH}$, phosphate and oxalate on the adsorption/desorption of arsenate on/from goethite. Soil Sci 2001, 166, 197-208.

(40) Zhao, H. S.; Stanforth, R. Competitive adsorption of phosphate and arsenate on goethite. Environ. Sci. Technol. 2001, 35, 4753-4757.

(41) Michel, F. M.; Ehm, L.; Antao, S. M.; Lee, P. L.; Chupas, P. J.; Liu, G.; Strongin, D. R.; Schoonen, M. A. A.; Phillips, B. L.; Parise, J. B. The structure of ferrihydrite, a nanocrystalline material. Science 2007, 316, 1726-1729.

(42) Hansel, C. M.; Benner, S. G.; Fendorf, S. Competing Fe(II)-induced mineralization pathways of ferrihydrite. Environ. Sci. Technol. 2005, 39, 7147-7153.

(43) Hansel, C. M. Bacterial and Geochemical controls on the reductive dissolution and secondary mineralization of iron (hydr) oxides. Ph.D. Dissertation, Stanford University. 2004.

(44) Kocar, B. D.; Fendorf, S. Thermodynamic Constraints on Reductive Reactions Influencing the Biogeochemistry of Arsenic in Soils and Sediments. Environmental science \& technology 2009, 43, 4871-4877. 
(45) Wang, Y. H.; Morin, G.; Ona-Nguema, G.; Menguy, N.; Juillot, F.; Aubry, E.; Guyot, F.; Calas, G.; Brown, G. E. Arsenite sorption at the magnetite-water interface during aqueous precipitation of magnetite: EXAFS evidence for a new arsenite surface complex. Geochimica Et Cosmochimica Acta 2008, 72, 2573-2586.

(46) Ball, J. W., Nordstrom, D.K.; Geological Survey (U.S.). User's manual for Wateq4f, with revised thermodynamic data base abd test cases fir calculating speciation of major, trace, nad reox elements in natural waters. 1991.

(47) Bhandari, N.; Reeder, R. J.; Strongin, D. R. Photoinduced Oxidation of Arsenite to Arsenate on Ferrihydrite. Environ. Sci. Technol. 2011, 45, 2783-2789.

(48) Amstaetter, K.; Borch, T.; Larese-Casanova, P.; Kappler, A. Redox Transformation of Arsenic by Fe(II)-Activated Goethite (alpha-FeOOH). Environ. Sci. Technol. 2010, 44, 102-108.

(49) Levenberg, K. A. A method for the solution of certain non-linear problems in least squares. Quartery Journal of Applied Mathematics 1944, 11, 164-168.

2010.

(50) Doherty, J. E. PEST-Model-Independent Parameter Estimation: User's Manual, 5th ed.

(51) Marquardt, D. W. An algorithm for the least-squares estimation of nonlinear parameters. SIAM 1963, 11, 431-441.

(52) Pierce, M. L.; Moore, C. B. Adsorption of Arsenite and Arsenate on Amorphous Iron Hydroxide. Water research 1982, 16, 1247-1253.

(53) Borch, T.; Masue, Y.; Kukkadapu, R. K.; Fendorf, S. Phosphate imposed limitations on biological reduction and alteration of ferrihydrite. Environmental science \& technology 2007, 41, 166172.

(54) Paige, C. R.; Snodgrass, W. J.; Nicholson, R. V.; Scharer, J. M. An arsenate effect on ferrihydrite dissolution kinetics under acidic oxic conditions. Water research 1997, 31, 2370-2382.

(55) Zachara, J. M.; Kukkadapu, R. K.; Fredrickson, J. K.; Gorby, Y. A.; Smith, S. C. Biomineralization of poorly crystalline Fe(III) oxides by dissimilatory metal reducing bacteria (DMRB). Geomicrobiol J 2002, 19, 179-207.

(56) Roden, E. E.; Zachara, J. M. Microbial reduction of crystalline iron(III) oxides: Influence of oxide surface area and potential for cell growth. Environ. Sci. Technol. 1996, 30, 1618-1628.

(57) Cornell, R. M.; Schwertmann, U.: The Iron Oxides. Structure, Properties, Reactions, Occurences and Uses. 1996.

(58) Coker, V. S.; Gault, A. G.; Pearce, C. I.; van der Laan, G.; Telling, N. D.; Charnock, J. M.; Polya, D. A.; Lloyd, J. R. XAS and XMCD evidence for species-dependent partitioning of arsenic during microbial reduction of ferrihydrite to magnetite. Environmental science \& technology 2006, 40, 7745-7750.

(59) Harvey, C. F.; Swartz, C. H.; Badruzzaman, A. B.; Keon-Blute, N.; Yu, W.; Ali, M. A.; Jay, J.; Beckie, R.; Niedan, V.; Brabander, D.; Oates, P. M.; Ashfaque, K. N.; Islam, S.; Hemond, H. F.; Ahmed, M. F. Arsenic mobility and groundwater extraction in Bangladesh. Science 2002, 298, 16021606. 
Table 1: Overview of the most important model variants employed to test arsenic mobilisation and attenuation in a column study ${ }^{1}$. All simulation include arsenic desorption by chemical disequilibrium during pore water replacement, arsenic release during reductive dissolution of iron, and adsorption of arsenic onto magnetite.

\section{Model variant Considered arsenic attenuation processes}

S1 As(III) sorption to ferrihydrite and magnetite. No As redox transformations.

S2 S1 $\quad$ As(III) incorporation with magnetite. No As redox transformations.

S3 S1 + (partial) As(III) oxidation.

S4a S1, S2, S3 + As(III) oxidation set at 25\%.

S4b S1, S2, S3 + As(III) oxidation set at 10\%. 


\begin{tabular}{|c|c|c|c|c|c|c|c|}
\hline \multirow[b]{2}{*}{ Parameter } & \multicolumn{5}{|c|}{ Model Variant } & \multirow[b]{2}{*}{$\begin{array}{l}\text { Lower } \\
\text { bound }\end{array}$} & \multirow[b]{2}{*}{$\begin{array}{l}\text { Upper } \\
\text { bound }\end{array}$} \\
\hline & S1 & S2 & $\mathbf{S 3}$ & S4a & S4b & & \\
\hline Initial concentration of aqueous As(III) & $1.3 \mathrm{E}-05$ & $1.3 \mathrm{E}-05$ & $1.6 \mathrm{E}-06$ & $3.2 \mathrm{E}-06$ & $3.45 \mathrm{E}-06$ & $1.00 \mathrm{E}-06$ & $1.00 \mathrm{E}-05$ \\
\hline Initial concentration of aqueous $\mathrm{As}(\mathrm{V})$ & 0 & 0 & $1.5 \mathrm{E}-05$ & $1.1 \mathrm{E}-05$ & $1.13 \mathrm{E}-05$ & $0.00 \mathrm{E}+00$ & $5.00 \mathrm{E}-05$ \\
\hline Sorption site density of weak sites (ferrihydrite) & 0.1 & 0.1 & 0.12 & 0.135 & 0.10 & $0.05^{\mathrm{c}}$ & $0.31^{\mathrm{a}}$ \\
\hline Sorption site density of strong sites (ferrihydrite) & 0.0025 & 0.0025 & 0.005 & 0.0026 & 0.005 & N/A & N/A \\
\hline Sorption site density of weak sites (magnetite) & 3.1 & 0.021 & 0.027 & 0.021 & 0.03 & $0.01^{\mathrm{a}}$ & $0.04^{\mathrm{a}}$ \\
\hline Sorption site density of strong sites (magnetite) & 0.008 & 0.0005 & 0.0007 & 0.00052 & 0.00068 & $\mathrm{~N} / \mathrm{A}$ & N/A \\
\hline \multicolumn{8}{|c|}{ Arsenate and Arsenite Surface Complexation Constants for Ferrihydrite } \\
\hline Hfo_wOH+ H3AsO3 $=$ Hfo_wH2AsO3 + & 5.91 & 5.56 & 5.6 & 5.58 & 5.51 & $4.02^{\mathrm{a}}$ & $5.56^{\mathrm{b}}$ \\
\hline $\mathrm{Hfo} \_w O H+\mathrm{AsO} 4-3+3 \mathrm{H}+=\mathrm{Hfo} \_\mathrm{wH} 2 \mathrm{AsO} 4+\mathrm{H}_{2} \mathrm{O}$ & NA & NA & 29.31 & 30 & 30.5 & $24.18^{\mathrm{b}}$ & $34.44^{\mathrm{b}}$ \\
\hline Hfo_wOH + AsO4-3 $+2 \mathrm{H}+=$ Hfo_wHAsO4- $+\mathrm{H} 2 \mathrm{O}$ & NA & NA & 23.9 & 23 & 23.18 & $23.18^{\mathrm{b}}$ & $24.43^{\mathrm{a}}$ \\
\hline Hfo_wOH+AsO4-3=Hfo_wAsO4-2 & NA & NA & 8.5 & 6.95 & 5.28 & $4.69^{\mathrm{a}}$ & $11.48^{\mathrm{b}}$ \\
\hline \multicolumn{8}{|c|}{ Arsenate and Arsenate Surface Complexation Constants for Magnetite } \\
\hline $\mathrm{Mag} \_w O H+A s O 3=\mathrm{Mag} \_w \mathrm{H}_{2} \mathrm{AsO} 3+\mathrm{H}_{2} \mathrm{O}$ & 5.61 & 5.61 & 5.6 & 5.23 & 6 & $0^{\mathrm{a}}$ & $7.67^{\mathrm{a}}$ \\
\hline Mag_wOH+AsO4-3+3H+= Mag_wH2AsO4 $+\mathrm{H}_{2} \mathrm{O}$ & NA & NA & 29.31 & 31.8 & 29.2 & 20 & 40 \\
\hline Mag_wOH+AsO4-3+2H+= Mag_wHAsO4- $+\mathrm{H} 2 \mathrm{O}$ & NA & NA & 29.31 & 26 & 23.18 & 19 & 29 \\
\hline $\mathrm{Mag} \_\mathrm{wOH}+\mathrm{AsO} 4-3=\mathrm{Mag} \_\mathrm{wOHAsO}_{4}{ }^{-3}$ & NA & NA & 8.5 & 10.2 & 5.65 & 5 & 13 \\
\hline \multicolumn{8}{|l|}{ Kinetic Reaction Rate Constants } \\
\hline Magnetite precipitation & $5.00 \mathrm{E}-06$ & $8.0 \mathrm{E}-04$ & $2.5 \mathrm{E}-04$ & $6.4 \mathrm{E}-05$ & $5.1 \mathrm{E}-05$ & $5.0 \mathrm{E}-05$ & $5.00 \mathrm{E}-03$ \\
\hline C_m (Eqn. 3) & 0.21 & 0.229 & 0.22 & 0.217 & 0.21 & 0.20 & 0.25 \\
\hline As inc. into magnetite (As:Fe molar ratio) & NA & 0.9 & NA & 0.34 & 0.35 & $5.0 \mathrm{E}-02$ & $1.0 \mathrm{E}+00$ \\
\hline As:Fe molar ratio from above & NA & $1: 1.7$ & NA & $1: 4.5$ & $1: 3.1$ & NA & NA \\
\hline$\alpha($ Eqn. 5) & NA & NA & $9.8 \mathrm{E}-09$ & 4.70E-09 & $6.0 \mathrm{E}-09$ & $3.0 \mathrm{E}-09$ & $6.00 \mathrm{E}-09$ \\
\hline Ferrihydrite dissolution & $1.10 \mathrm{E}-08$ & $1.10 \mathrm{E}-08$ & $1.10 \mathrm{E}-08$ & $1.07 \mathrm{E}-08$ & $1.01 \mathrm{E}-08$ & $1.00 \mathrm{E}+09$ & $5.00 \mathrm{E}-08$ \\
\hline
\end{tabular}



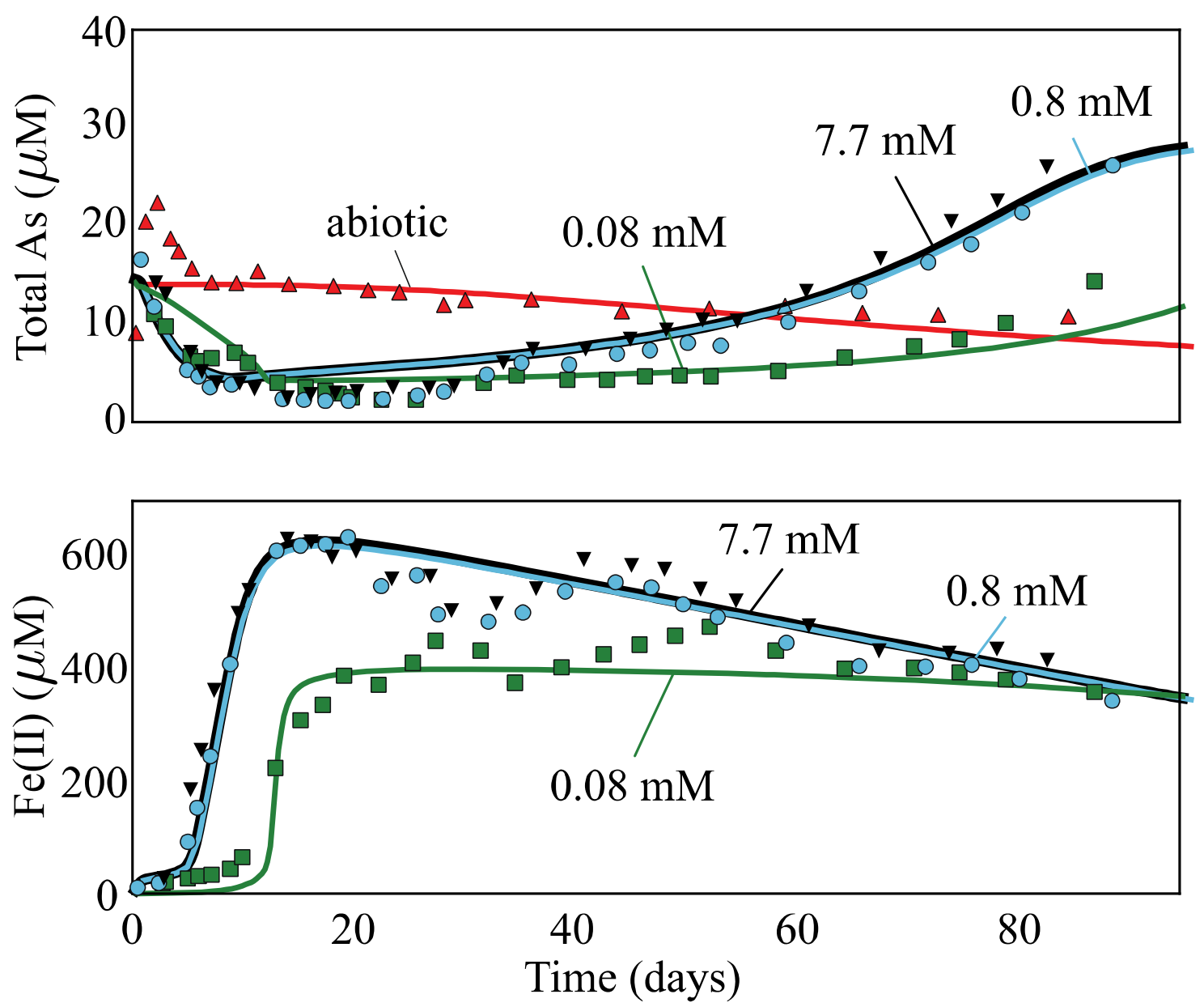

646 Figure 1: Simulation $(S 4 b)$ and experimental results for arsenic and ferrous iron for four columns 647 amended with varying lactate concentrations. Symbols represent observed concentrations for the abiotic 648 (red triangle), $7.7 \mathrm{mM}$ (blue circle), $0.8 \mathrm{mM}$ (inverted black triangle), and $0.08 \mathrm{mM}$ (green square) 649 column experiments from Tufano and Fendorf ${ }^{1}$ respectively. Solid lines represent the calibrated model. 
658
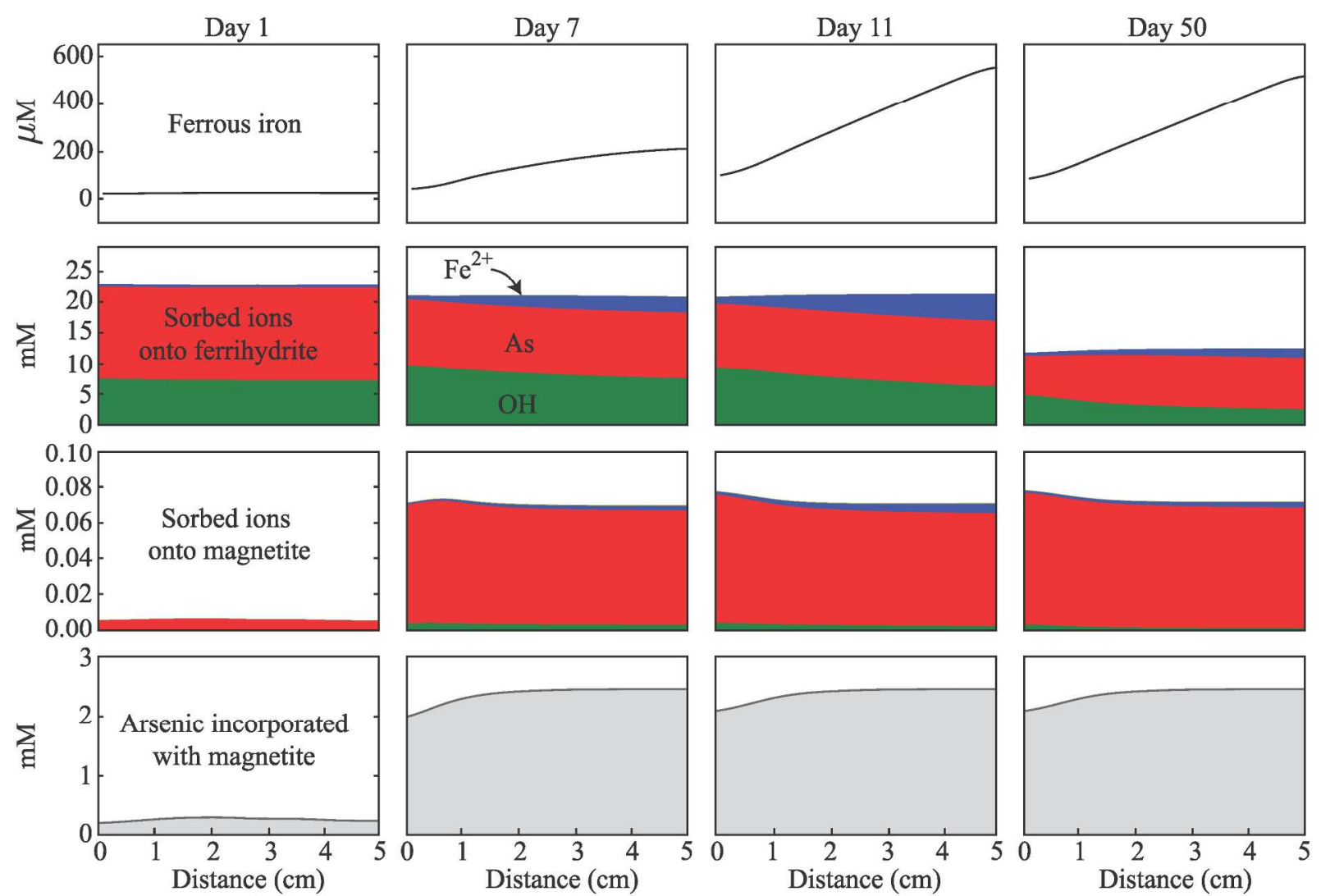

660 Figure 2: $S 4 b$ simulated column profiles for $7.7 \mathrm{mM}$ lactate amended column (flow from left to right).

661 Row 1: Aqueous ferrous iron concentrations. Row 2 and 3 are major sorbed ions onto ferrihydrite and 662 magnetite respectively; green is hydroxyl group, red is total arsenic, and blue is ferrous iron. Row 4:

663 Arsenic incorporated into transforming magnetite. 

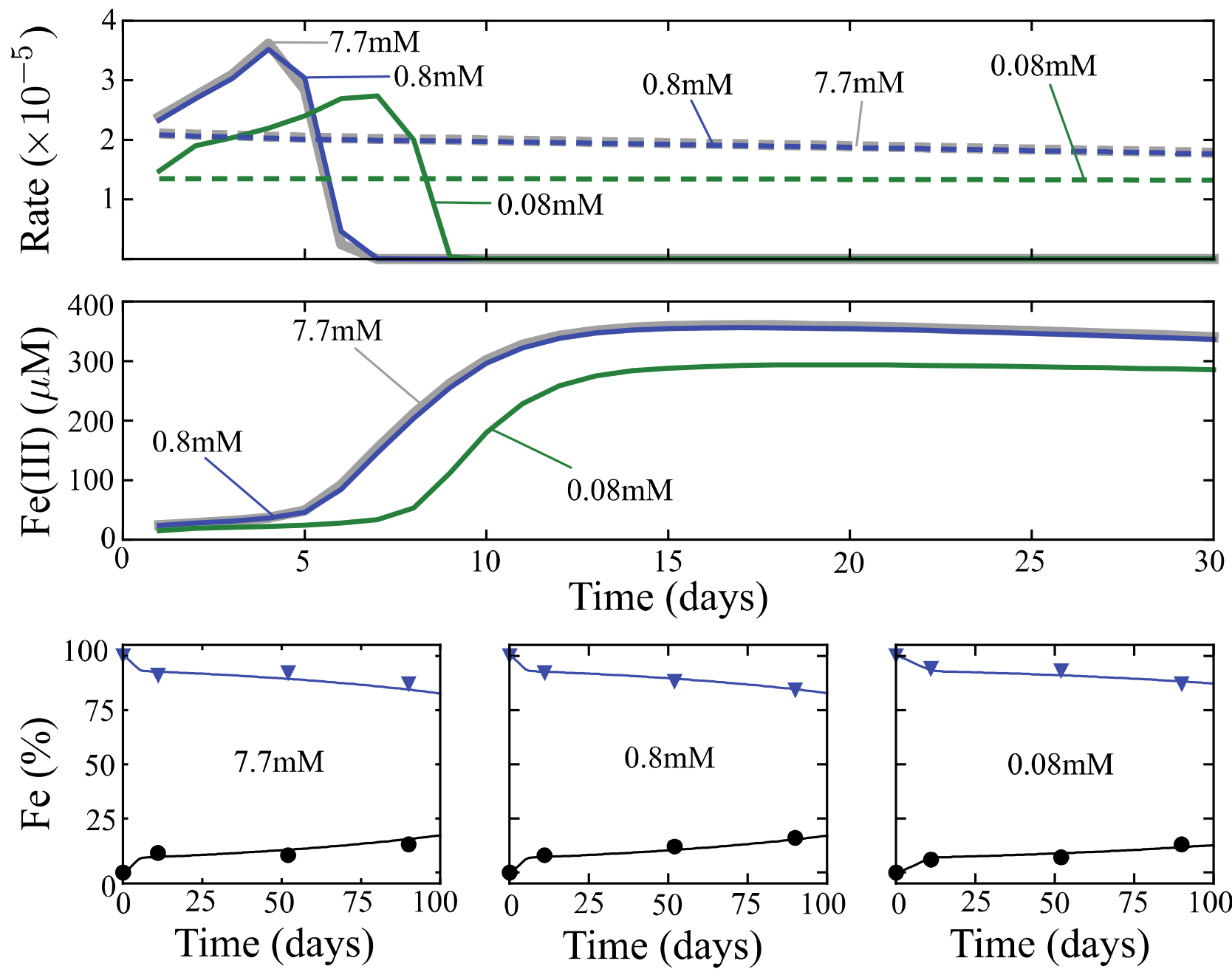

673
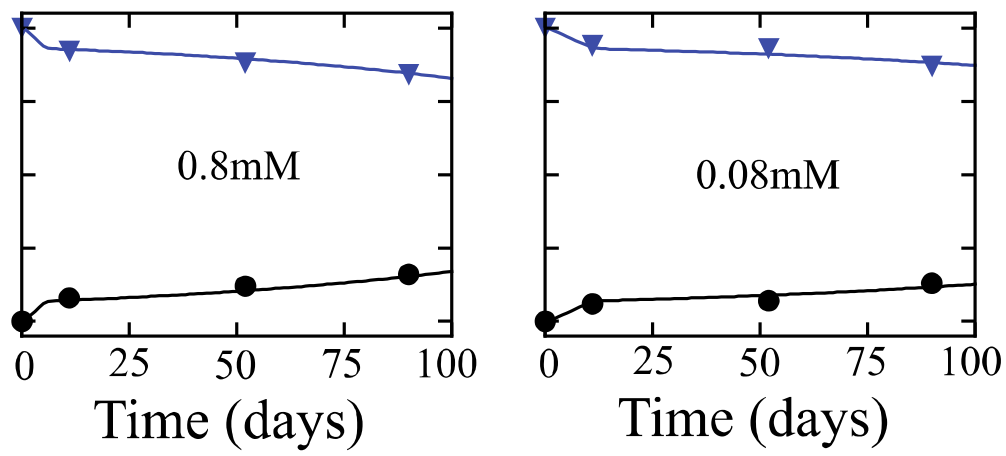

674 Figure 3: $S 4 b$ simulation results at midpoint along column. Experimental results were taken from

675 terminated columns. Top panel: Magnetite precipitation rate (solid lines) and ferrihydrite dissolution

676 rate (dashed lines) for each of the lactate amended models. Middle panel: Simulated aqueous ferrous

677 iron concentrations at column effluent end. Bottom panel: Simulation (solid line) and experimental 678 results (symbol) of the iron transformation from ferrihydrite (in blue) to magnetite (in black) for each 679 lactate amended model.

680 


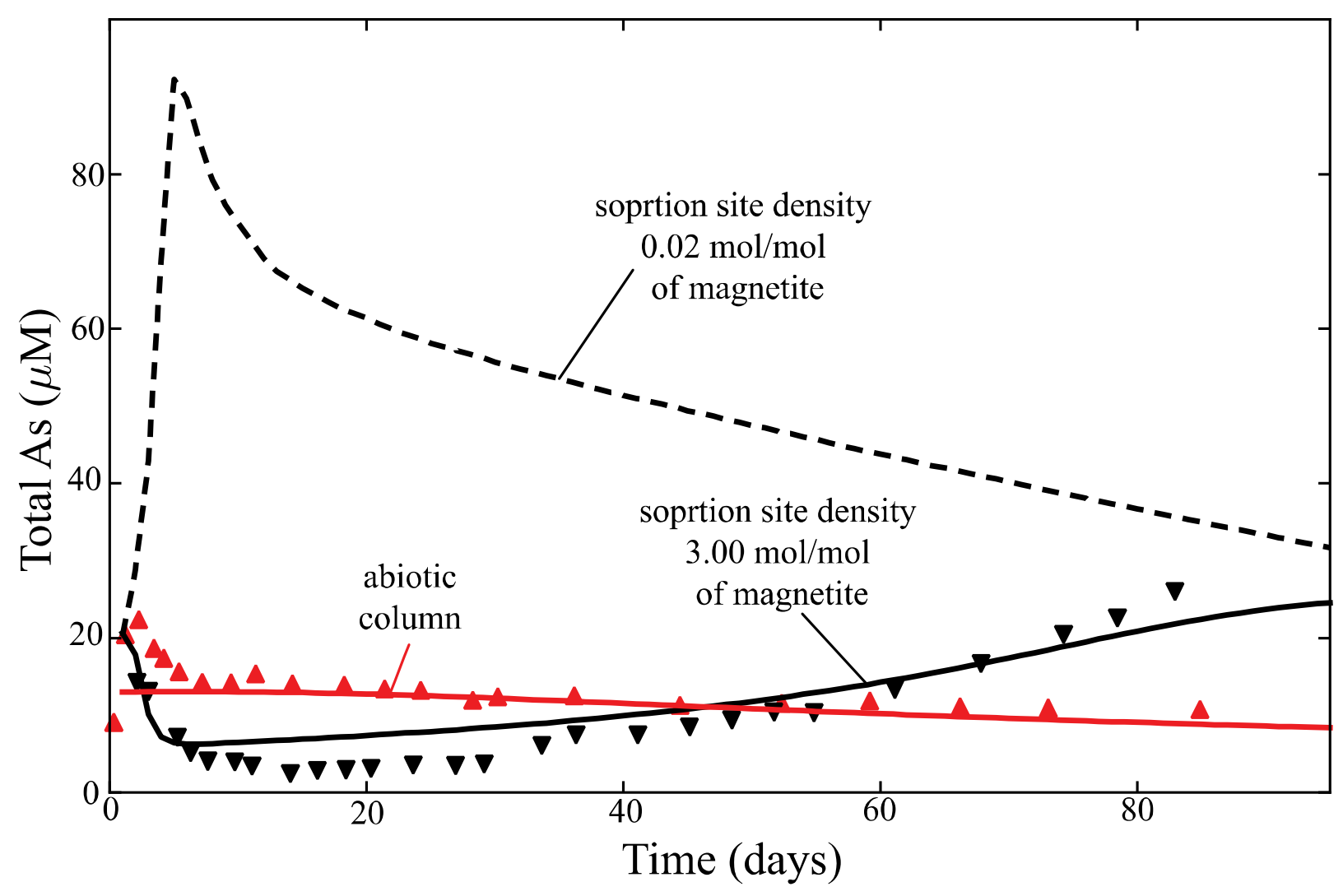

687 Figure 4: Simulated (dashed and solid lines, model variant S1) and experimental results (symbols) at 688 the column effluent end: Simulation results with just As(III) for 7.7mM lactate and abiotic columns. The 689 black solid line represents As(III) with a sorption site density of magnetite approximately 120 times of 690 that reported by Dixit and Hering. ${ }^{17}$ 


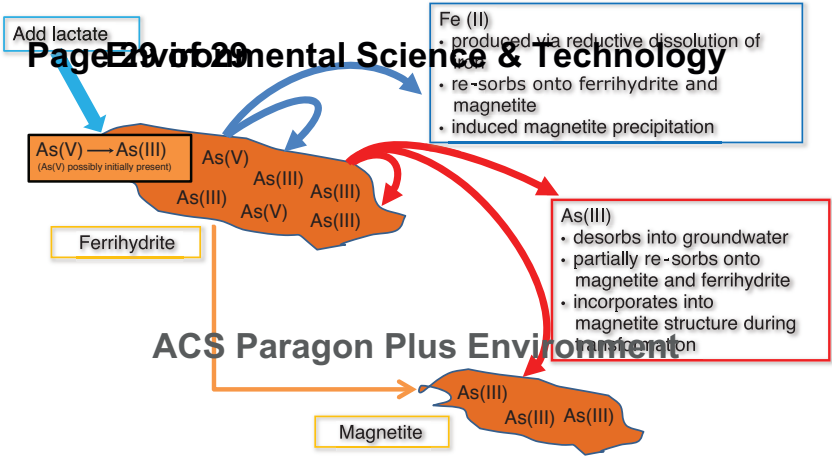

